\title{
Bronchodilator effect of apigenin and luteolin, two components of Dracocephalum kotschyi on isolated rabbit trachea
}

\author{
Hassan Sadraei $^{*{ }^{\circledR}}$, Seyed Mostapha Ghanadian², Gholamreza Asghari ${ }^{2}{ }^{\circledR}$, Aminreza Gavahian $^{1}$ \\ ${ }^{1}$ Department of Pharmacology and Toxicology, School of Pharmacy and Pharmaceutical Sciences, Isfahan University of Medical Sciences, Isfahan, I.R. \\ Iran \\ ${ }^{2}$ Department of Pharmacognosy and Isfahan Pharmaceutical Sciences Research Center, School of Pharmacy and Pharmaceutical Sciences, Isfahan \\ University of Medical Sciences, Isfahan, I.R. Iran
}

\section{A R T I C L E I N F O}

Article Type:

Original Article

\section{Article History:}

Received: 27 January 2019

Accepted: 17 February 2019

\section{Keywords:}

Dracocephalum kotschyi

Apigenin

Luteolin

Trachea

Smooth muscle

\begin{abstract}
A B S T R A C T
Introduction: Dracocephalum kotschyi is a native Iranian plant with antispasmodic activities on smooth muscles such as ileum and uterus. However, so far antispasmodic effect of $D$. kotschyi on tracheal smooth muscle has not been reported. Therefore, the objective of this research was to investigate antispasmodic activity of $D$. kotschyi extract and two of its components luteolin and apigenin on rabbit tracheal contraction in vitro.

Methods: Rabbits were euthanized by carbon dioxide and the trachea was dissected and immersed in a Tyrode's solution. Tracheal rings were prepared and mounted vertically in an organ bath at $37^{\circ} \mathrm{C}$ and gassed continuously with $\mathrm{O}_{2}$. The tracheal ring preparations were contracted with acetylcholine $(\mathrm{ACh})$ and $\mathrm{KCl}$. The isotonic tension was recorded before and after addition of aminophylline, apigenin, luteolin or flavonoids rich extract of D. kotschyi. Flavonoids rich extract were prepared from $D$. kotschyi using solvent-solvent fractionation technique.

Results: Standard drug aminophylline, prevented tracheal ring preparation contracted with ACh. Cumulative addition of aminophylline also attenuated tonic contraction induced by $\mathrm{KCl}$ on tracheal smooth muscle. D. kotschyi extract at concentration ranges of $32-512 \mu \mathrm{g} / \mathrm{mL}$ in a concentration dependent manner inhibited $\mathrm{KCl}$ and $\mathrm{ACh}$ induced tracheal contraction. Apigenin and luteolin (range 16-512 $\mu \mathrm{g} / \mathrm{mL}$ ) relaxed $\mathrm{KCl}$ and ACh-induced contraction of tracheal smooth muscle in vitro in a concentration-dependent manner.

Conclusion: This study demonstrated that $D$. kotschyi extract is a relaxant of tracheal smooth muscle. The relaxant effect of $D$. kotschyi extract could be due to its flavonoids component such as apigenin and luteolin.
\end{abstract}

Implication for health policy/practice/research/medical education:

This paper provides pharmacological evidence for bronchodilatory action of apigenin and luteolin two component of Dracocephalum kotschyi. Therefore, they might be useful in bronchospasm conditions such as asthma and chronic bronchitis.

Please cite this paper as: Sadraei H, Ghanadian SM, Asghari G, Gavahian A. Bronchodilator effect of apigenin and luteolin, two components of Dracocephalum kotschyi on isolated rabbit trachea. J Herbmed Pharmacol. 2019;8(4):281-286. doi: 10.15171/ jhp.2019.41.

\section{Introduction}

Dracocephalum (dragonhead) is a genus of more than 60 species of flowering plants growing with various sizes (1). At least eight species of Dracocephalum (family Lamiaceae) have been identified in Iran (2). Dracocephalum kotschyi Boiss. is a scientific name of one species in the genus Dracocephalum and known as Zaringiah in Iran (3). Zaringiah (D. kotschyi) is a medicinal plant native to temperate regions and grows in high altitudes mountainous locations of Iran $(4,5)$. In some part of Iran, local people traditionally use Zaringiah for treatment of arthritis, gastrointestinal disorders as well as for alleviation of asthma (6). Modern pharmacological studies confirm that $D$. kotschyi possesses antispasmodic and anti-inflammatory properties (7-10). Nevertheless, $D$. kotschyi is enriched in many bioactive constituents with wide range of pharmacological properties (11-13). Antispasmodic and anti-inflammatory effects of D. kotschyi 
extract are attributed to its flavonoids constituents including apigenin and luteolin $(14,15)$.

It has been reported that apigenin has anti-allergic effect in allergic induced airways reaction of mice and has exhibited anti-inflammatory activity in experimental model of asthma $(16,17)$. Furthermore, apigenin prevent proliferation and migration of airways smooth muscle cells by inhibiting transforming growth factor- $\beta_{1}$ $\left(\right.$ TGF- $\left.\beta_{1}\right)$ a key inflammatory factor in asthma $(18,19)$. Similar effect has been reported for luteolin. For instant, luteolin alleviates airway hyperactivity, airways mucus overproduction and asthmatic features in experimental models (20-22). In addition, apigenin and luteolin ameliorate features of bleomycin induced lung fibrosis $(23,24)$. Although, asthma is an inflammatory disease of airways, however, bronchoconstriction also plays a significant role in breathless of asthmatic patients. As mentioned above, D. kotschyi extract as well as apigenin and luteolin have relatively potent antispasmodic activities on isolated ileum and uterus smooth muscles $(9,10,14,15)$. Therefore, the objective of this research is to investigate bronchodilatory effect of $D$. kotschyi extract for comparison for luteolin and apigenin.

\section{Materials and Methods}

Zaringiah was collected from cultivated garden in Shahankoah at $2650 \mathrm{~m}$ altitude from sea level. Shahankoah mountain rang are situated in Meidanak village in Feridonshar (Isfahan, Iran) and is native environment in which Zaringiah growth naturally. The plant was identified as D. kotschyi by a botanist (Mohamad Asfa) from Department of Natural Resource in Isfahan Province. A voucher specimen has been deposited in the School of Pharmacy of Isfahan University of Medical Sciences (No: 1519). Grassy branches of D. kotschyi were cut during flowering season and dried in shade. Dried plant materials were grounded to fine powder by an electronic grainer (Keep, Korea).

Extraction and fractionation procedures

Powdered material of $D$. kotschyi was extracted with $70 \%$ ethanol at room temperature using percolation extraction technique (25). The solvents of hydroalcoholic extract were evaporated under reduced pressure at $60^{\circ} \mathrm{C}$ on a rotary evaporator. Concentrated hydroalcoholic extract was then subject to liquid-liquid fractionation with chloroform and ethylacetate in the order of their increasing polarity to obtain respective fractions. Initially with sever shaking and stirring the hydroalcoholic extract (100 g) was dissolved in mixtures of distilled water and chloroform (1:1). The chloroform fraction was decanted and the process repeated by addition equal volume of fresh chloroform. The remaining aqueous fraction was fractionated with ethylacetate five times. Combined ethylacetate fraction was concentrated to dryness under reduced pressure $\left(30^{\circ} \mathrm{C}\right)$ on a rotary evaporator to give ethylacetate fraction of $D$. kotschyi.

Flavonoids contents of separated fractions were assessed by aluminum chloride colorimetric method as described before (15). Ethylacetate fraction possessed highest contents of flavonoids and therefore considered as flavonoids rich fraction for this study.

\section{Tissue preparation and isotonic force recording}

Domestic rabbits bred in open filed farm in Esfahan were housed in School of Pharmacy and Pharmaceutical Sciences animal house at room temperature with free access to food and water. Animals were handled according to international guideline for handing laboratory animals (26) approved by the University Ethical Committee (IR. MUI.REC.1396.3.816). For preparation of bladder, a rabbit was placed in a glass chamber with two inlet and outlet slots and euthanized with carbon dioxide gas. The euthanized animal was removed and placed on laboratory bench and longitudinal incisures were made in the frontal section of neck. The trachea was cleaned of adhering tissues and dissected out and placed in oxygenated Tyrode's solution (see drug and solution). Connective and fatty tissues were carefully trimmed off and the trachea was cut into transverse strips of 2-3 adjacent cartilage rings. Four tracheal rings were tied together with cotton thread in such a way that smooth muscle layer was lined up vertically. The prepared tissues were secured in an organ bath for isotonic muscle contraction recording, using a force displacement transducer (Harvard Apparatus) coupled to an oscillograph (Harvard Apparatus, England). The oscillograph was calibrated according to apparatus manual and adjusted to the optimal length for muscle contraction for each tissue. The tissues were placed constantly under $1 \mathrm{~g}$ passive tension in the Tyrode's solution at $37^{\circ} \mathrm{C}$ and continuously gassed with oxygen. The tissues were allowed to settle to their normal basal tension while being washed several times with Tyrode's solution.

Tracheal contraction studies

Tracheal smooth muscles contractions were induced by addition of potassium chloride $(80 \mathrm{mM} \mathrm{KCl})$ or acetylcholine (ACh, $100 \mu \mathrm{g} / \mathrm{mL}$ ) into the organ bath. ACh remained $1.5 \mathrm{~min}$ in contact with the tissue before it was washed out with fresh Tyrode's solution. ACh was added to organ bath at 10-minute intervals. When reproducible tissue responses were established, contractile responses of the trachea to $\mathrm{ACh}$ or $\mathrm{KCl}$ were recorded in the present of the extract, apigenin, luteolin or aminophylline. Inhibitory effects of the tested compounds were examined in cumulative manner for $\mathrm{KCl}$ response while $\mathrm{ACh}$ response was assessed $10 \mathrm{~min}$ after incubation of test compound in a non-cumulative manner.

Drug and solutions

The Tyrode's composition was $136.9 \mathrm{mM} \mathrm{NaCl}, 1.8 \mathrm{mM}$ $\mathrm{CaCl}_{2}, 2.68 \mathrm{mM} \mathrm{KCl}, 11.9 \mathrm{mM} \mathrm{NaHCO}, 1.05 \mathrm{mM} \mathrm{MgCl}_{2}$, 
$0.42 \mathrm{mM} \mathrm{NaH} \mathrm{PO}_{4}$ and $5.55 \mathrm{mM}$ glucose. The extract was prepared in dimethylsulphoxide (DMSO) as $20 \mathrm{mM}$ stock solution. Luteolin and apigenin were dissolved in DMSO as $20 \mathrm{mM}$ stock solutions. Further dilutions (1 in 10) were made in 50\% DMSO. Aminophylline $(25 \mathrm{mg} / \mathrm{mL}$ ampoule, Caspian, Iran) was diluted in distilled water. $\mathrm{KCl}$ (2M) and ACh (100mM) stock solution were prepared and diluted in distilled water. First stock of ACh was acidified with $1 \%$ acetic acid to increase stability. Apigenin and luteolin were purchased from Aktin Chemical Inc (China). Acetylcholine was from Sigma. Other chemicals were from Merck.

\section{Contraction assessments and analysis}

Bronchial smooth muscle contraction was measured as amplitude of recorded contraction from baseline and expressed as percentage of pretreated control response. Mean and standard error of mean (SEM) were calculated for each group of data $(n=6)$. Full concentration inhibitory response curves were plotted for assessment of $\mathrm{IC}_{50}$ value (inhibitory concentration causing $50 \%$ of maximum response). Statistical differences between the groups were analyzed by Student $t$ test or one-way analysis of variance. $P$ values less than 0.05 were considered statistically significant. SigmaPlot computer program was used for statistical analysis and plotting graphs for calculation of $\mathrm{IC}_{50}$ values.

\section{Results}

Tracheal smooth muscles suspended under $1 \mathrm{~g}$ tension in Tyrode's solution gradually relaxed to a stable baseline within 15-30 minutes. Addition of $\mathrm{KCl}(80 \mathrm{mM})$ produced a sustained contraction. Addition of ACh into the organ bath contracted the tissues within 90 seconds contact time. After washing the tissue with fresh Tyrode's solution, the tissues relaxed to initial baseline position.

After repeatable response to ACh was established effective concentrations of aminophylline, apigenin, luteolin and D. kotschyi extract were determined in a series of pilot experiments. Aminophylline reduced tracheal smooth muscle contractile responses to both $\mathrm{KCl}$ and $\mathrm{ACh}$. However, with $1.28 \mathrm{mg} / \mathrm{mL}$ aminophylline in the bath still $20 \%$ and $40 \%$ of $\mathrm{KCl}$ and $\mathrm{ACh}$ responses, respectively were remained (Figure 1). Apigenin also inhibited tissues responses to both $\mathrm{KCl}$ and $\mathrm{ACh}$ in a concentration dependent manner. The inhibitory effect of apigenin was observed with bath concentration of 16 $\mu \mathrm{g} / \mathrm{mL}$ and when apigenin concentration was added up to $512 \mu \mathrm{g} / \mathrm{mL}, \mathrm{KCl}$ response was abolished and only $7 \%$ of ACh response remained (Figure 2). The inhibitory concentration causing $50 \%$ of maximum response $\left(\mathrm{IC}_{50}\right)$ was calculated as $66 \pm 7 \mu \mathrm{g} / \mathrm{mL}$ and $80 \pm 14 \mu \mathrm{g} / \mathrm{mL}$ for $\mathrm{KCl}$ and $\mathrm{ACh}$, respectively $(\mathrm{n}=6)$. Luteolin had similar inhibitory effect as apigenin on tracheal smooth muscle contractions. The first concentration of luteolin $(16 \mu \mathrm{g} /$ $\mathrm{mL}$ ) had no effect on either $\mathrm{KCl}$ or ACh responses. By

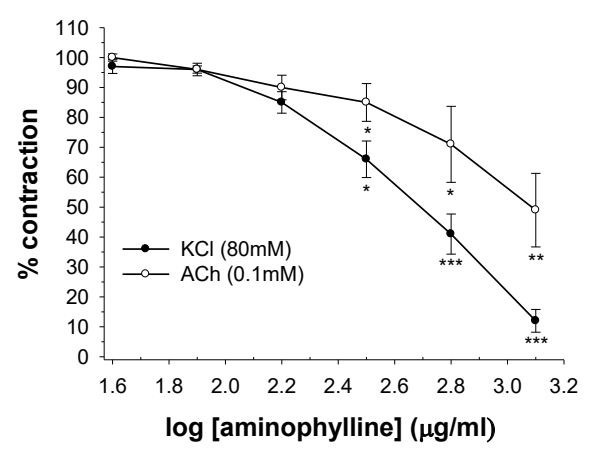

Figure 1. Effect of aminophylline on $\mathrm{KCl}$ and acetylcholine (ACh) induced contractions in rabbit isolated trachea. Data are present as mean \pm SEM $(n=6)$. Stars show statistically significant difference in absence and in presence of increasing aminophylline concentration in the bath $\left({ }^{*} P<0.05\right.$, ${ }^{* *} P<0.01,{ }^{* * *} P<0.001$, Student $t$ test).

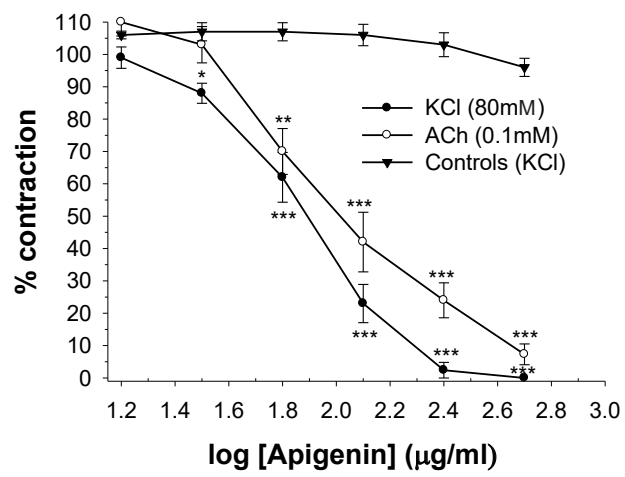

Figure 2. Effect of apigenin on $\mathrm{KCl}$ and acetylcholine (ACh) induced contractions in rabbit isolated trachea. Concentration response curve was constructed using two folds increment in bath concentration. Data are present as mean \pm SEM $(n=6)$. There was no statistically significant inhibition in the vehicle (DMSO) treated control groups (ANOVA). Stars show statistically significant difference in apigenin treated group with their corresponding concentration in the vehicle treated group $\left({ }^{*} P<0.05\right.$, ${ }^{\star *} P<0.01,{ }^{* *} P<0.001$, Student's $t$ test).

increasing luteolin concentration to $32 \mu \mathrm{g} / \mathrm{mL}$ response to $\mathrm{KCl}$ was attenuated while ACh response was not affected. Higher concentrations of luteolin in a concentration dependent fashion inhibited tracheal contraction induced by both $\mathrm{KCl}$ and $\mathrm{ACh}$ (Figure 3). The $\mathrm{IC}_{50}$ values of luteolin for inhibition of $\mathrm{KCl}$ and $\mathrm{ACh}$ responses were $65 \pm 4 \mu \mathrm{g} / \mathrm{mL}$ and $90 \pm 12 \mu \mathrm{g} / \mathrm{mL}$, respectively. D. kotschyi extract at concentration ranges of $32 \mu \mathrm{g} / \mathrm{mL}$ to $1 \mathrm{mg} / \mathrm{mL}$ concentration dependently reduced contractile responses to ACh with $\mathrm{IC}_{50}$ value of $340 \pm 68 \mu \mathrm{g} / \mathrm{mL}$ (Figure 4). After washing the tissues with fresh Tyrode's solution, contractile response to $\mathrm{KCl}$ and $\mathrm{ACh}$ was gradually restored. Equivalent volume of drugs vehicle (DMSO) did not caused any significant reduction in $\mathrm{KCl}$ or $\mathrm{ACh}$ responses in the vehicle treated time matched control tissues (Figures 2, 3 and 4).

\section{Discussion}

Respiratory tract is a compact organ situated in the 


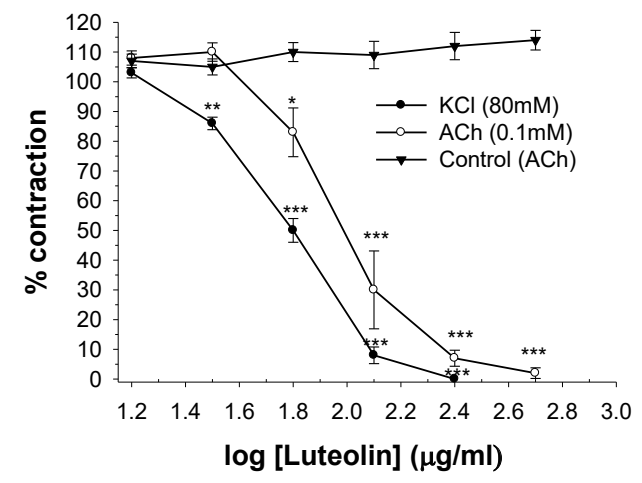

Figure 3. Effect of luteolin on $\mathrm{KCl}$ and acetylcholine (ACh) induced contractions in rabbit isolated trachea. Concentration response curve was constructed using two folds increment in bath concentration. Data are present as mean \pm SEM $(n=6)$. There was no statistically significant inhibition in the vehicle (DMSO) treated control groups (ANOVA). Stars show statistically significant difference in luteolin treated group with their corresponding concentration in the vehicle treated group $\left({ }^{*} P<0.05\right.$, ${ }^{* *} P<0.01,{ }^{* * *} P<0.001$, Student's $t$ test).

thorax and is responsible for constant gas exchange. Air is drawn into the lungs through trachea and its branches (27). Trachea consists of C-shape rings of cartilage joined by smooth muscle to complete encircles. These rings continuous down the bronchi and bronchioles (28). Bronchial inflammation of respiratory tract induces airway narrowing and decrease in lung function in condition such as bronchitis and asthma (29). These conditions may cause obstruction of airflow from the lungs. Release of inflammation mediators directly or indirectly via activation of vagus nerve, further narrows the bronchial tubes (30). Parasympathetic nerves activation cause bronchoconstriction through muscarinic receptors (30). The primary stage of smooth muscle contraction involves elevation of intracellular calcium ions, activation of myosin light chain kinase and phosphorylation of myosin light chain $(27,28)$. Addition of ACh into organ bath constricted bronchial rings by activating muscarinic $\mathrm{M}_{3}$ receptors as in the case of vagus nerve activation. These muscarinic receptors are associated with phospholipase- $\mathrm{C}$ activation and release of $\mathrm{Ca}^{2+}$ from intracellular stores via inositol triphosphate $\left(\mathrm{IP}_{3}\right)$ production $(27,28)$. Addition of high concentration of $\mathrm{KCl}$ into the organ bath, induced membrane depolarization and activation of voltage gated $\mathrm{Ca}^{2+}$ channels and smooth muscle contraction (31).

The standard drug, aminophylline, is a methylxanthine which inhibits phosphodiesterase with resultant increase in intracellular cAMP and/or cGMP concentration (32). These second messengers reverse the phosphorylation of myosin light chain and cause relaxation. Furthermore, they reduce intracellular calcium ion concentration by reducing $\mathrm{Ca}^{2+}$ entry and promoting $\mathrm{Ca}^{2+}$ storage and $\mathrm{Ca}^{2+}$ expulsion from the cell (33). Interfering with final stage of smooth muscle contraction could explain why aminophylline inhibits both $\mathrm{ACh}$ and $\mathrm{KCl}$ induced contractions. Apigenin and luteolin completely inhibited

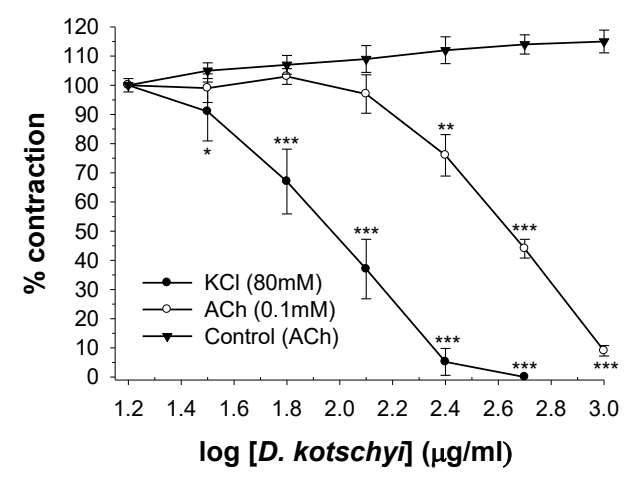

Figure 4. Effect of Dracocephalum kotschyi flavonoids rich extract on $\mathrm{KCl}$ and acetylcholine (ACh) induced contractions in rabbit isolated trachea. Concentration response curve was constructed using two folds increment in bath concentration. Data are present as mean \pm SEM $(n=6)$. There was no inhibition in the vehicle (DMSO) treated control groups. Stars show statistically significant difference in the extract treated group with their corresponding concentration in the vehicle treated control group $\left({ }^{\star} P<0.05\right.$, ${ }^{* *} P<0.01,{ }^{* *} P<0.001$, Student's $t$ test).

$\mathrm{ACh}$ and $\mathrm{KCl}$ induced contractions in isolated bronchial rings. Therefore, like aminophylline they can be regarded as potent bronchodilator agents. It has been reported that luteolin inhibits phosphodiesterase (34) which may contribute to its relaxant effect on smooth muscle. It has been suggested that aminophylline not only relaxes smooth muscle in the respiratory tract but also suppresses airway stimuli involving in inflammatory process of asthma. In fact, asthma is a complicated disease which involves secretion of ranges of inflammatory mediators and airway remodeling (35). Bronchial remodeling in asthma is associated with increase smooth muscle mass, thickening of the bronchial wall and cell migration (35). Activation of inflammatory cells, such as mast cells or T-lymphocytes and secretion of a range of inflammatory mediators, contributes to bronchial inflammation and bronchoconstriction (35). Transforming growth factor- $\beta_{1}$ $\left(\right.$ TGF- $\left.\beta_{1}\right)$ is a cytokine that is released and is well known inflammatory mediator with significant role in airway remodeling and asthma progression (35). It has been reported that apigenin inhibits TGF- $\beta$-induced fibroblast to myofibroblast transition which is known as a key event in asthma progression in human lung fibroblast population (18). This may indicate that apigenin could prevent structural remodeling in asthma. Apigenin also inhibited TGF- $\beta_{1}$ induced proliferation and migration of smooth muscle cells and airway remodeling in animal asthma model (19). Furthermore, apigenin inhibits allergic airway reactions in ovalbumin induced asthma in mice (17) and exhibits anti-inflammatory activity in animal model of asthma (16). Similar anti-nflammatory actions have been reported for luteolin. For instant luteolin alleviates hyperactivity in ovalbumin sensitized mice and prevents mucus overproduction, which is a common symptom in asthmatic patients (21-22).

In this research we demonstrated that both apigenin 
and luteolin could relax isolated rabbit tracheal smooth muscles contraction induced by ACh and high extracellular concentration of potassium chloride. These findings further support the idea that apigenin and luteolin are suitable lead compounds to be considered for treatment of asthma and chronic bronchitis. Apigenin and luteolin are two known flavonoids components of $D$. kotschyi extract (36).

In the present study we have demonstrated that flavonoids rich extract of $D$. kotschyi extract concentration-dependently suppressed $\mathrm{KCl}$ and $\mathrm{ACh}$-induced contractions of rabbit tracheal ring. D. kotschyi extract also reported to have antiinflammatory and anti-allergic activities and these actions have been attributed to its flavonoids contents (13-15). The flavonoids components in the D. kotschyi extract are found in free or glycosides forms $(36,37)$. Glycosides form of apigenin include apigenin-7-O-apiosylglucoside, apigenin8-O-glucoside, apigenin-7-O-glucoside, apigenin-6-Oglucoside, apigenin-6-7-diglucoside, 7-methyoapigenin and 7-methoxyapigenin (36,37). Luteolin has close structural similarity to apigenin and shares common glycosides forms. Glycosides forms of flavonoids are polar molecules due to sugar moiety and extractable with hydroalcoholic solution, while aglycones (sugar free from) of apigenin and luteolin are extracted with less polar solvents such as ethylacetate. Our previous researches have revealed that in vitro studies mainly the aglycones forms of apigenin and luteolin exhibit antispasmodic activity (38). Nevertheless, when administered orally, the sugar moiety is removed from the glycosides forms and the active forms are released (15). This explain why D. kotschyi extract is more effective when is given orally. This experiment supports the idea that apigenin and luteolin contributes to bronchodilatory effect of $D$. kotschyi extract. However, assessment of total flavonoids content of the extract shows that they are accounting for relatively small percentage of the total extract (15). Therefore, it is very likely that apart from apigenin and luteolin, other constituents of the extract have a share in relaxant effect of the extract which needs to be investigated.

\section{Conclusion}

Current therapy for treatment of asthma includes bronchodilator drugs which relax bronchial smooth muscles. Corticosteroids are also used for prevention and reduction of inflammation. Previous studies have demonstrated that apigenin and luteolin possess potent anti-inflammatory activities in animal asthmatic models. Our finding clearly shows that apigenin and luteolin are direct airway smooth muscle relaxants and their bronchodilatory actions are comparable to that of aminophylline.

\section{Acknowledgments}

This project was part of Pharm D. thesis of Aminreza Gavahian as a Pharm D. student at Isfahan University of
Medical Sciences.

\section{Author's contribution}

HS was responsible for the project and pharmacological studies. MG and GA supervised preparation of the extract. AG performed the experiments. HS was responsible for preparing the article. All read the final version and confirmed its publication.

\section{Conflict of interests}

The authors report no conflicts of interest. The authors are responsible for the content and writing of this article.

\section{Ethical considerations}

Animal care and experiments were performed in accordance with the guidelines for the care and use of laboratory animals of the Isfahan University of Medicine Sciences. The project was confirmed by the ethical committee of this university (IR.MUI.REC.1396.3.816).

\section{Finding/Support}

This research project financially was supported by Research Department of Isfahan University of Isfahan University of Medical Sciences (Project No.396816).

\section{References}

1. Rechinger KH. Dracocephalum. In: Iranica F, Rechinger KH, ed. Akademische Druck-U. Vol. 150. Verlagsanstalt, Graz, Austria; 1986. 218-231.

2. Sonboli A, Gholipour A, Mirjalili MH, Amini-Rad M. Molecular characterization of Iranian Dracocephalum (Lamiaceae) species based on RAPD data. Acta Bio Szeged. 2011;55(2):227-30.

3. Mozaffarian V. A dictionary of Iranian plant names. Tehran: Farhang Moaser; 2012:292-3. [Persian].

4. Zargari A. Medicinal plants. 4th ed. Tehran: Tehran University Publication; 1990:42-5. [Persian].

5. Mirheydar H. Maaref Giahi. Vol 2. Tehran: Daftare Nasher Farhange Eslami; 1995. 170-6. [Persian].

6. Naghibi F, Mosaddegh M, Mohammadi Motamed M, Ghorbani A. Labiatae family in folk medicine in Iran: from ethnobotany to pharmacology. Iran J Pharm Res. 2005;4(2):63-79. doi: 10.22037/ijpr.2010.619.

7. Kalantar K, Gholijani N, Mousaei N, Yazdani M, Amirghofran Z. Investigation of Dracocephalum kotschyi plant extract on the effective inflammatory transcription factors and mediators in activated macrophages. Antiinflamm Antiallergy Agents Med Chem. 2018;17(1):3949. doi: 10.2174/1871523017666180608081656.

8. Sadraei H, Asghari G, Khanabadi M, Minaiyan M. Antiinflammatory effect of apigenin and hydroalcoholic extract of Dracocephalum kotschyi on acetic acid-induced colitis in rats. Res Pharm Sci. 2017;12(4):322-9. doi: 10.4103/17355362.212050.

9. Sadraei H, Asghari G, Alinejad M. Comparison of antispasmodic effect of hydroalcoholic extract of Dracocephalum kotschyi Boiss. in rat uterus and ileum. Res Pharm Sci. 2016;11(4):284-92. doi: 10.4103/1735- 
5362.189295.

10. Sadraei H, Asghari G, Kasiri F. Antispasmodic effect of Dracocephalum kotschyi hydroalcoholic extract on rat ileum contraction. Res Pharm Sci. 2015;10(5):446-52.

11. Sadraei H, Asghari G, Shahverdi F. Antidiarrhoeal assessment of hydroalcoholic and hexane extracts of Dracocephalum kotschyi Boiss. and apigenin in mice. Res Pharm Sci. 2016;11(3):200-9.

12. Sajjadi SE, Movahedian Atar AM, Yektaian A. Antihyperlipidemic effect of hydroalcoholic extract, and polyphenolic fraction from Dracocephalum kotschyi Boiss. Pharm Acta Helv. 1998;73(3):167-70.

13. Amirghofran Z, Azadbakht M, Karimi MH. Evaluation of the immunomodulatory effects of five herbal plants. J Ethnopharmacol. 2000;72(1-2):167-72.

14. Sadraei H, Ghanadian M, Asghari G, Sekhavati N. Antispasmodic activity of apigenin and luteolin, two components of Dracocephalum kotschyi extract, on rat ileum contractions. J Herbmed Pharmacol. 2018;7(2):1005. doi: 10.15171/jhp.2018.17.

15. Sadraei H, Ghanadian SM, Moazeni S. Inhibitory effect of hydroalcoholic and flavonoids extracts of Dracocephalum kotschyi, and its components luteolin, apigenin and apigenin-4'-galactoside on intestinal transit in mice. J Herbmed Pharmacol. 2019;8(1):8-13. doi: 10.15171/ jhp.2019.02.

16. Li RR, Pang LL, Du Q, Shi Y, Dai WJ, Yin KS. Apigenin inhibits allergen-induced airway inflammation and switches immune response in a murine model of asthma. Immunopharmacol Immunotoxicol. 2010;32(3):364-70. doi: $\quad 10.3109 / 08923970903420566$.

17. Choi JR, Lee CM, Jung ID, Lee JS, Jeong YI, Chang JH, et al. Apigenin protects ovalbumin-induced asthma through the regulation of GATA-3 gene. Int Immunopharmacol. 2009;9(7-8):918-24. doi: 10.1016/j.intimp.2009.03.018.

18. Wojcik KA, Skoda M, Koczurkiewicz P, Sanak M, Czyz J, Michalik M. Apigenin inhibits TGF-betal induced fibroblast-to-myofibroblast transition in human lung fibroblast populations. Pharmacol Rep. 2013;65(1):164-72.

19. Li LH, Lu B, Wu HK, Zhang H, Yao FF. Apigenin inhibits TGF-beta1-induced proliferation and migration of airway smooth muscle cells. Int J Clin Exp Pathol. 2015;8(10):12557-63.

20. Das M, Ram A, Ghosh B. Luteolin alleviates bronchoconstriction and airway hyperreactivity in ovalbumin sensitized mice. Inflamm Res. 2003;52(3):101-6.

21. Shen ML, Wang CH, Lin CH, Zhou N, Kao ST, Wu DC. Luteolin attenuates airway mucus overproduction via inhibition of the GABAergic system. Sci Rep. 2016;6:32756. doi: $10.1038 /$ srep32756.

22. Zhang GM, Gong GQ, Li LL, Yang LN, Wang Y. Effects of Luteolin on the Proliferation of Rat Lung Fibroblasts. Chin J Nat Med. 2009;7(4):297-300. doi: 10.1016/S18755364(10)60022-2.

23. Chen L, Zhao W. Apigenin protects against bleomycininduced lung fibrosis in rats. Exp Ther Med. 2016;11(1):2304. doi: 10.3892/etm.2015.2885.
24. Chen CY, Peng WH, Wu LC, Wu CC, Hsu SL. Luteolin ameliorates experimental lung fibrosis both in vivo and in vitro: implications for therapy of lung fibrosis. J Agric Food Chem. 2010;58(22):11653-61. doi: 10.1021/jf1031668.

25. Samuelsson G. Drugs of natural origin. Stockholm: Swedish Pharmaceutical Press; 1999:48-9.

26. Committee for the update of the guide for the care and use of laboratory animals National Research Council. Guide for the care and use of laboratory animals. Washington DC: The National Academies Press; 2010:37-11.

27. Stephens NL. Airway smooth muscle. Lung. 2001;179:33373.

28. Ouedraogo N, Roux E. Physiology of airway smooth muscle contraction: an overview. J Pulm Respir Med. 2014;4(6):221. doi: 10.4172/2161-105X.1000221.

29. Amrani Y, Panettieri RA. Airway smooth muscle: contraction and beyond. Int $\mathrm{J}$ Biochem Cell Biol. $2003 ; 35(3): 272-6$.

30. van der Velden VH, Hulsmann AR. Autonomic innervation of human airways: structure, function, and pathophysiology in asthma. Neuroimmunomodulation. 1999;6(3):145-59. doi: 10.1159/000026376.

31. Ratz PH, Berg KM, Urban NH, Miner AS. Regulation of smooth muscle calcium sensitivity: $\mathrm{KCl}$ as a calciumsensitizing stimulus. Am J Physiol Cell Physiol. 2005;288(4):C769-83. doi: 10.1152/ajpcell.00529.2004.

32. Krzanowski JJ, Polson JB. Mechanism of action of methylxanthines in asthma. J Allergy Clin Immunol. 1988;82(2):143-5.

33. Tilley SL. Methylxanthines in asthma. Handb Exp Pharmacol. 2011(200):439-56. doi: 10.1007/978-3-64213443-2_17.

34. Yu MC, Chen JH, Lai CY, Han CY, Ko WC. Luteolin, a non-selective competitive inhibitor of phosphodiesterases $1-5$, displaced $[3 \mathrm{H}]$-rolipram from high-affinity rolipram binding sites and reversed xylazine/ketamine-induced anesthesia. Eur J Pharmacol. 2010;627(1-3):269-75. doi: 10.1016/j.ejphar.2009.10.031.

35. Bara I, Ozier A, Tunon de Lara JM, Marthan R, Berger P. Pathophysiology of bronchial smooth muscle remodelling in asthma. Eur Respir J. 2010;36(5):1174-84. doi: 10.1183/09031936.00019810.

36. Gohari AR, Saeidnia S, Matsuo K, Uchiyama N, Yagura T, Ito M. et al. Flavonoid constituents of Dracocephalum kotschyi growing in Iran and their trypanocidal activity. Nat Med. 2003;57(60:250-2.

37. Saeidnia S, Gohari AR, Uchiyama N, Ito M, Honda G, Kiuchi F. Two new monoterpene glycosides and trypanocidal terpenoids from Dracocephalum kotschyi. Chem Pharm Bull (Tokyo). 2004;52(10):1249-50. doi: $10.1248 /$ cpb.52.1249.

38. Sekhavati N. Bioactivity guided isolation of active fraction of Dracocephalum kotschyi extract responsible for antispasmodic activity on rat ileum [Thesis]. Isfahan: School of Pharmacy and Pharmaceutical Sciences, Isfahan University of Medical Sciences; 2018. [Persian]. 